\title{
Cu-catalyzed N-3-Arylation of Hydantoins Using Diaryliodonium Salts
}

\author{
Linn Neerbye Berntsen, Ainara Nova, David S. Wragg, and Alexander H. Sandtorv*
}

Cite This: Org. Lett. 2020, 22, 2687-2691

Read Online

ABSTRACT: A general Cu-catalyzed, regioselective method for the $\mathrm{N}$-3arylation of hydantoins is described. The protocol utilizes aryl(trimethoxyphenyl)iodonium tosylate as the arylating agent in the presence of triethylamine and a catalytic amount of a simple $\mathrm{Cu}$-salt. The method is compatible with structurally diverse hydantoins and operates well with neutral aryl groups or aryl groups bearing weakly donating/withdrawing elements. It is also applicable for the rapid diversification of pharmaceutically relevant hydantoins.

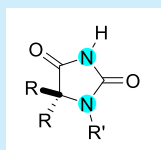

$\mathrm{R}$ and $\mathrm{R}^{\prime}$ can be $\mathrm{H}$

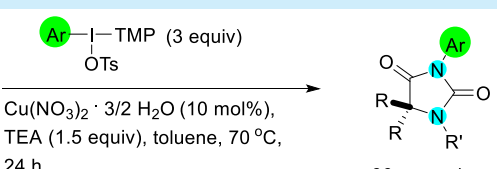

$24 \mathrm{~h}$

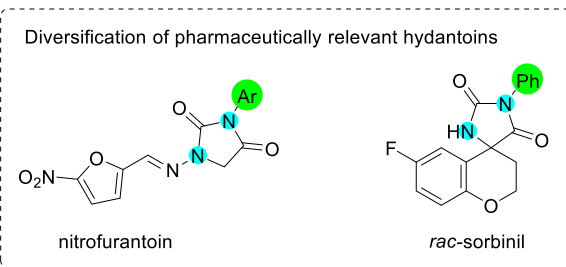

$\mathrm{H}$ ydantoin is a heterocyclic scaffold with numerous application areas. ${ }^{1}$ The structure has an impressive range of biological activities, ${ }^{2}$ likely due to its high density of intermolecular interaction points. ${ }^{3}$ It is encountered in several drugs, such as nilutamide, sorbinil, and nitrofurantoin, and constitutes a key molecular component of various agrochemicals. ${ }^{4}$ The nucleus also has synthetic versatility, ${ }^{5}$ for example, in the preparation of amino acids. ${ }^{6}$ Of particular interest are $\mathrm{N}$-arylated hydantoins due to their important biological applications (Figure 1).

The primary access point to $N$-arylhydantoins (and other substituted hydantoins) is through de novo cyclization reactions from linear precursors (Scheme 1). ${ }^{8}$ A plethora of such transformations is known, ${ }^{9}$ and each method has advantages and limitations. The direct functionalization of the hydantoin nucleus offers a complementary approach where
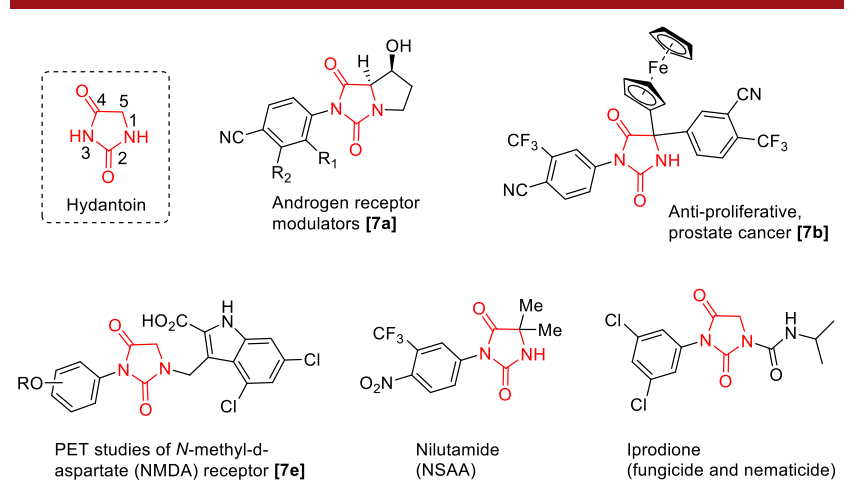

Figure 1. Some $\mathrm{N}$-3-arylhydantoins with biological properties.
Scheme 1. Prior Work

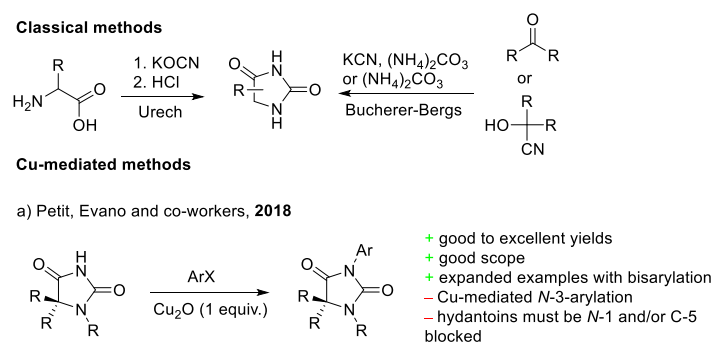

Cu-catalyzed methods

b) Lopez-Alvarado and co-workers, 1992 / 1996
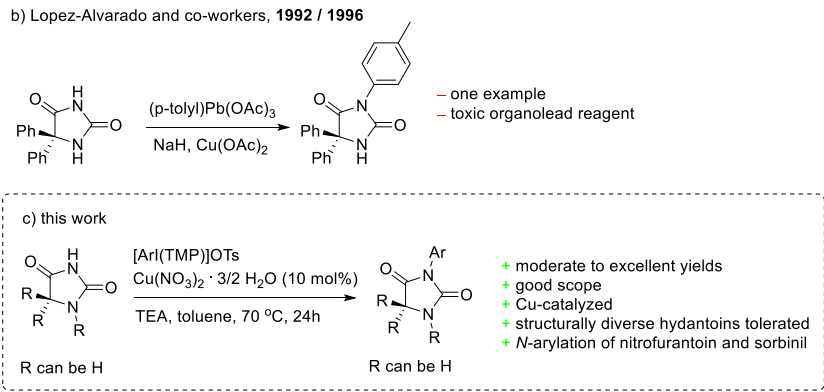

Received: February 18, 2020

Published: March 23, 2020 
the substituent(s) of interest are chemo- and regioselectively forged onto the ring itself. This scenario allows divergent modifications of hydantoins as well as potentially quicker and cheaper access to such structures. Direct functionalization remains underdeveloped, perhaps due to its challenging nature. $^{7 \mathrm{c}, 10}$

For example, the direct N-3-phenylation of unsubstituted hydantoin has, to the best of our knowledge, not been described in the literature.

Recently, a breakthrough was achieved by Petit, Evano, and coworkers (Scheme 1a), who divulged a Cu-mediated $\mathrm{N}$ arylation protocol. ${ }^{11}$ The method exhibited a good reaction scope and mostly good yields. However, it suffered from two disadvantages: (i) the use of stoichiometric $\mathrm{Cu}$ and (ii) clear structural limitations of the hydantoin starting material. Whereas 5,5-disubstituted hydantoins were regioselectively arylated at the $\mathrm{N}-3$ position, removing one or both of the C-5 substituents led to significant competing arylation at $N$-1, limiting the substrate scope. The $\mathrm{Cu}$-catalyzed $\mathrm{N}$-arylation of hydantoins is largely unexplored, and only sparse and highly specialized examples are reported in the literature (Scheme 1b). ${ }^{7 c, 12}$ Herein we describe a general $\mathrm{Cu}$-catalyzed process for $\mathrm{N}$-3-arylation of hydantoins, a complementary method to the current $\mathrm{Cu}$-mediated protocol (Scheme 1).

Diaryliodonioum salts ${ }^{13}$ have received increasing attention over the past decade, ${ }^{14}$ partially due to their ability to transfer aryl groups to nucleophiles. ${ }^{15}$ Our reaction discovery process led to the revelation that unsymmetrical iodonium salts regioselectively arylated the $\mathrm{N}$-3-position of hydantoin in the presence of a simple copper salt and tertiary amine under mild conditions. In contrast, phenyl iodide was an inefficient arylating agent under $\mathrm{Cu}$-catalyzed conditions and did not successfully couple to the hydantoin nucleus.

An overview of the optimization studies is provided in Scheme 2. The best conditions (entry 1) involved the use of excess aryl(trimethoxyphenyl)iodonium tosylate in the presence of copper(II)nitrate sesquihydrate and triethylamine in toluene at $70{ }^{\circ} \mathrm{C}$ for $24 \mathrm{~h}$. Under these conditions, trace amounts $(<5 \%)$ of the $N$-1-regioisomer were typically

Scheme 2. Key Controls and Optimization Data for the Reaction

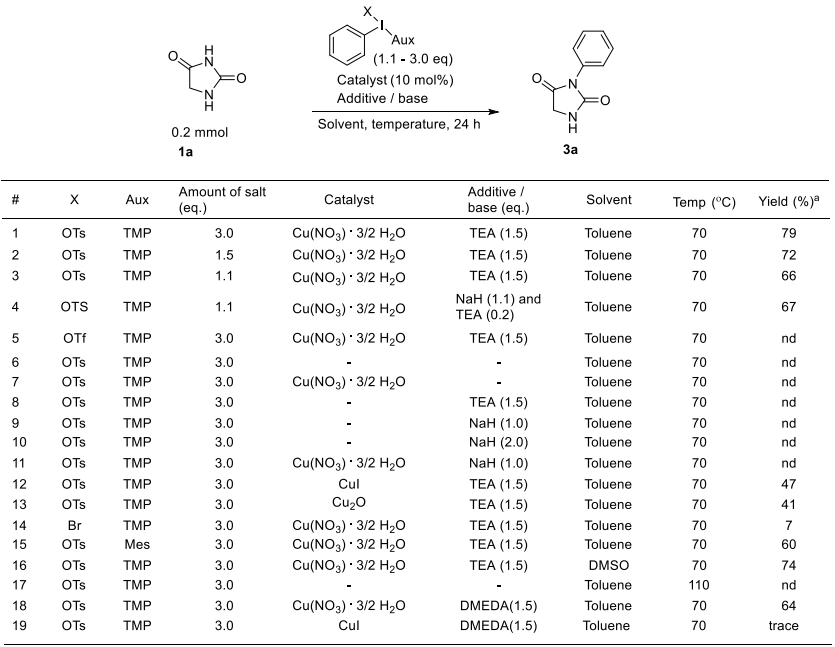

${ }^{a}$ Yield measured using mesitylene as an internal standard in the ${ }^{1} \mathrm{H}$ NMR analysis of the crude reaction mixture. observed as well as small amounts of the corresponding $N, N^{\prime}$-bisarylated product $(3-10 \%)$. The process was also efficient and regioselective when the excesses of phenyl(trimethoxyphenyl)iodonium tosylate was reduced to 1.5 or 1.1 equiv (entries 2 and 3), although the desired target was produced in slightly reduced yield. If a small reduction in yield is tolerable, then the process can therefore be performed with improved atom efficiency. The scope and limitations of the process are shown in Scheme 3.

Scheme 3. Scope and Limitations of the Catalytic N-3Arylation Process ${ }^{c}$

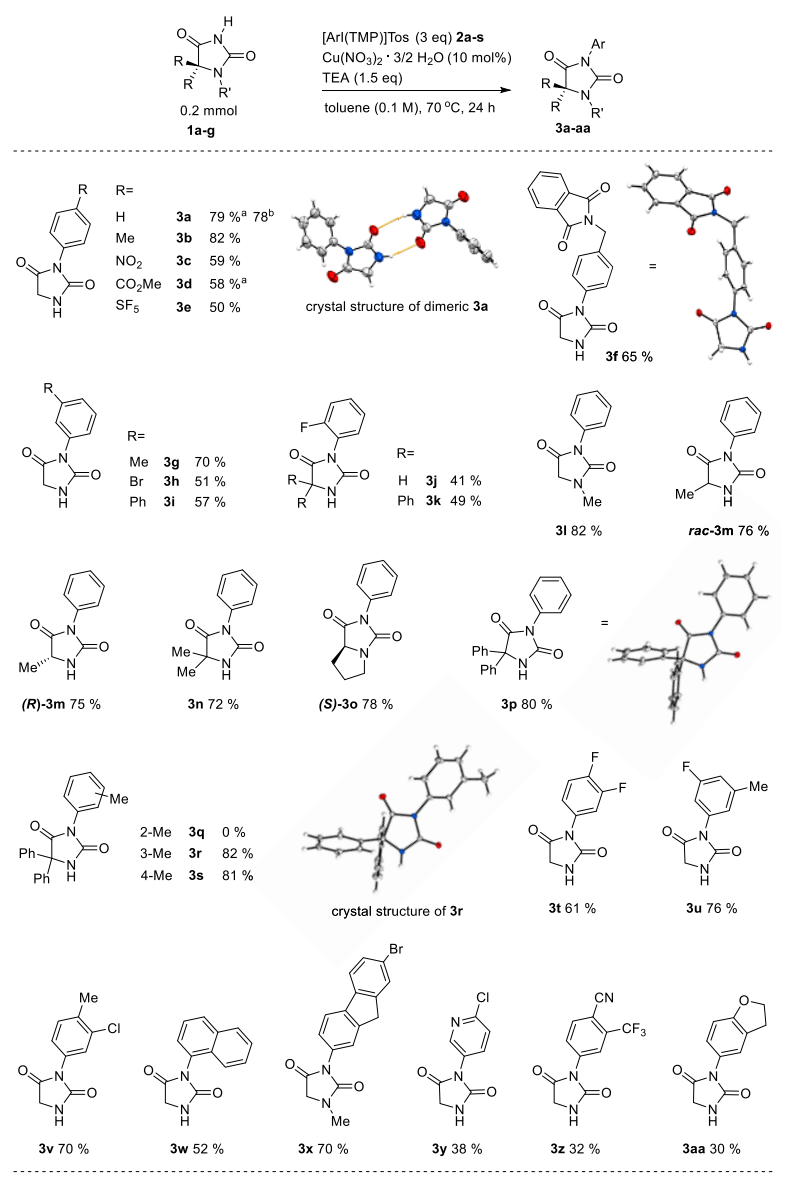

${ }^{a_{5}} \mathrm{~mol} \%$ of catalyst employed. ${ }^{b}$ Reaction performed using $1 \mathrm{mmol}$ of diaryl iodonium salt and extended reaction time $(31 \mathrm{~h}) .{ }^{c}$ Conditions: Hydantoin $\mathbf{1 a}-\mathrm{g}(0.2 \mathrm{mmol}, 1.0$ equiv), $[\operatorname{ArI}(\mathrm{TMP})] \mathrm{Tos} \mathbf{2 a}-\mathbf{s}(0.6$ mmol, 3.0 equiv), $\mathrm{Cu}\left(\mathrm{NO}_{3}\right)_{2} \cdot 3 / 2 \mathrm{H}_{2} \mathrm{O}(0.02 \mathrm{mmol}, 0.1$ equiv), triethylamine (TEA) $(0.3 \mathrm{mmol}, 1.5$ equiv), and toluene $(2 \mathrm{~mL})$.

Pleasingly, the N-3 arylation proceeded smoothly with structurally diverse hydantoins, including structures lacking substituents on $\mathrm{C}-5$ or $\mathrm{N}-1 .^{11}$ Aryl rings bearing neutral or weakly electron-donating/withdrawing groups were efficiently transferred to the N-3-position on the hydantoin ring. This trend was also observed for disubstituted aryl rings. The method was sensitive to iodonium salts bearing aryl groups congested at the $o$-position, likely due to steric crowding around the $\mathrm{Cu}$-center in the catalytic process. The relatively small fluoride atom was tolerated, providing the corresponding hydantoins $3 \mathbf{j}$ and $\mathbf{3 k}$ in moderate yields. The more demanding $o$-methyl group was not tolerated under our conditions, and the coupled product $\mathbf{3 q}$ was not observed in the post reaction 
mixture. The mild conditions did not cause epimerization at the C-5-position of the hydantoin ring. The coupled chiral hydantoin products $(R)-3 \mathrm{~m}$ and $(S)$-3o were obtained in good yield with stereoretention, as indicated by polarimetric analysis. Strongly electron-poor and electron-rich aryl groups were less efficient substrates (3c,d, e), and N-3-arylated hydantoins $3 \mathbf{y}$, $3 \mathbf{z}$, and 3 aa were isolated in modest yield.

To our delight, the method was also applicable to a small selection of cyclic imide-type structures ${ }^{16}$ (Scheme 4 ) such as

Scheme 4. N-Arylation of Other N-H Bonds ${ }^{a}$

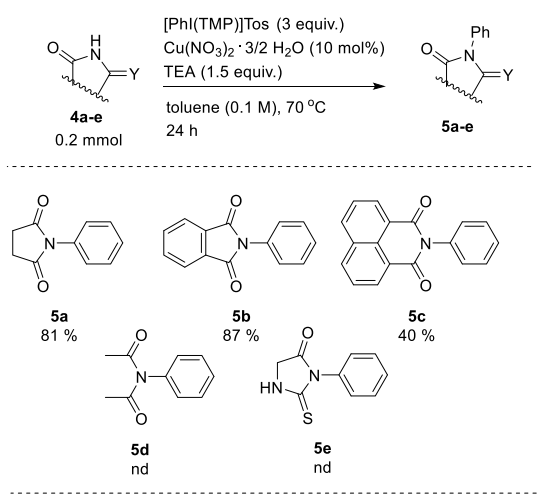

${ }^{a}$ Conditions: Imide $4 a-d ~(0.2 \mathrm{mmol}, 1.0$ equiv), $[\operatorname{ArI}(\mathrm{TMP})]$ Tos $\mathbf{2 a}$ ( $0.6 \mathrm{mmol}, 3.0$ equiv), $\mathrm{Cu}\left(\mathrm{NO}_{3}\right)_{2} \cdot 3 / 2 \mathrm{H}_{2} \mathrm{O}(0.02 \mathrm{mmol}, 0.1$ equiv), triethylamine (TEA) $(0.3 \mathrm{mmol}, 1.5$ equiv), and toluene $(2 \mathrm{~mL})$.

succinimide $4 a$ and phtalamide $4 b$, exemplifying the usefulness of the method in an expanded structural space. The linear imide $4 \mathbf{d}$ did not produce the desired product $\mathbf{5 d}$, indicating that the method is not applicable to linear imides, likely due to their less constrained confirmation compared with cyclic imides. Thiohydantoin $4 \mathrm{e}$ did not react under our conditions.

To illustrate the practicality of the method, the well-known antibiotic drug nitrofurantoin $6^{17}$ was $N$-3-arylated in good yield, providing a small library of nitrofurantoin derivatives $7 \mathbf{a}-\mathbf{c}$ (Scheme 5). The racemate of the aldose reductase inhibitor sorbinil $\mathbf{8}^{18}$ was also $\mathrm{N}$-3-arylated in good yield.

Scheme 5. Regioselective $\mathrm{N}$-Arylation of Pharmaceutically Relevant Agents ${ }^{a}$
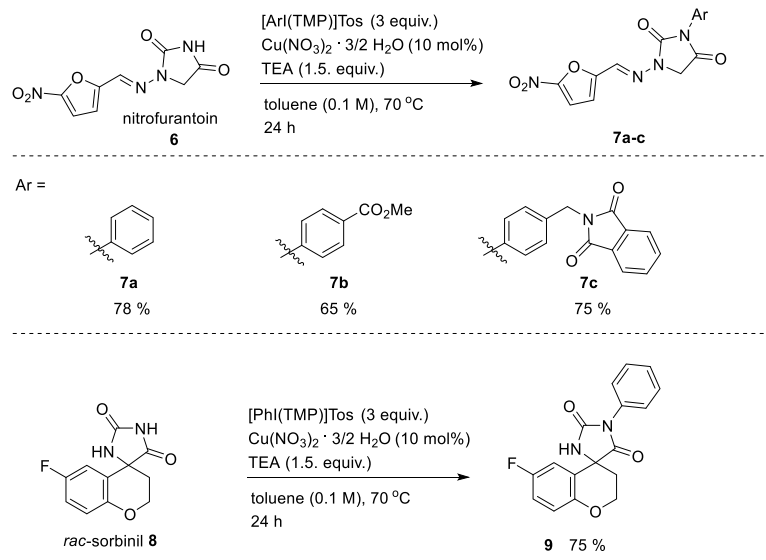

${ }^{a}$ Conditions: hydantoin 6 or $8(0.2 \mathrm{mmol}, 1.0$ equiv), [ArI(TMP)]Tos (0.6 mmol, 3.0 equiv), $\mathrm{Cu}\left(\mathrm{NO}_{3}\right)_{2} \cdot 3 / 2 \mathrm{H}_{2} \mathrm{O}$ (0.02 mmol, 0.1 equiv), triethylamine (TEA) $(0.3 \mathrm{mmol}, 1.5$ equiv), and toluene ( 2 $\mathrm{mL})$.
These examples illustrate the potential methods for the rapid diversification of pharmaceutically relevant agents and highlight the advantage of direct functionalization.

Two different mechanisms involving the $\mathrm{Cu}(\mathrm{I}) / \mathrm{Cu}(\mathrm{III})$ species could be envisaged for this process (Scheme 6).

Scheme 6. Two Mechanistic Proposals for the Cu-Catalyzed $\mathrm{N}$-Arylation Process

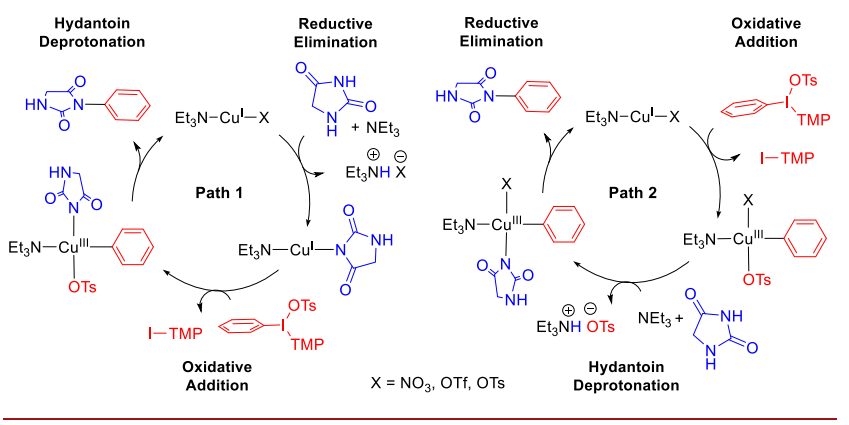

Pathway 1 corresponds to the mechanism proposed for Ullman-type $\mathrm{C}-\mathrm{N}$ bond coupling reactions using aryl iodides. ${ }^{19}$ In this process, a $\mathrm{Cu}(\mathrm{I})$ species would deprotonate the hydantoin prior to the oxidative addition of the iodonium tosylate. In Pathway 2, the first step would consist of an oxidative addition of the iodonium salt followed by the deprotonation of hydantoin. The latter pathway has been proposed in $\mathrm{Cu}$-catalyzed arylation reactions involving diaryliodonium salts. ${ }^{20}$ In both pathways, the final product is formed by reductive elimination of the $\mathrm{Cu}$ (III) aryl amido intermediate. The use of $\mathrm{Cu}(\mathrm{II})$ precatalyst for $\mathrm{Cu}(\mathrm{I})$ mediated reactions is precedented. ${ }^{21}$ Both one-electron reduction and disproportionation mechanisms have been proposed for the reduction of $\mathrm{Cu}^{22}$ We believe that in the two mechanisms TEA acts as both a $\mathrm{Cu}$ ligand and base, driving the deprotonation of hydantoin. This double function was corroborated by using a catalytic amount of TEA and $\mathrm{NaH}$ as a base (see entry 4 , Scheme 2 ). The tosylate anion may also play an important role when coordinated to the $\mathrm{Cu}$ center, assisting the intramolecular deprotonation of hydantoin at the $\mathrm{N}-3$ position, which is the most acidic. ${ }^{22}$ This could account for the lower yield observed when using bromide or the less basic OTf anion (see entries 5 and 14, Scheme 2).

In summary, we have reported the first general $\mathrm{Cu}$-catalyzed method for the regioselective $\mathrm{N}$-3-arylation of hydantoins. The method utilizes unsymmetrical iodonium salts, a simple $\mathrm{Cu}$ salt, and triethylamine under mild conditions. The method is robust and flexible, operates well, with weakly electrondonating and -withdrawing groups, proceeds without epimerization at C-5 of hydantoin, and smoothly arylates structurally varied hydantoins, including pharmaceutically relevant structures such as nitrofurantoin and rac-sorbinil. In-depth mechanistic investigations are currently underway.

\section{ASSOCIATED CONTENT}

\section{Supporting Information}

The Supporting Information is available free of charge at https://pubs.acs.org/doi/10.1021/acs.orglett.0c00642.

Detailed experimental procedures and full spectroscopic data for all new compounds (PDF) 


\section{Accession Codes}

CCDC 1975309, 1975600, 1975603, and 1986195 contain the supplementary crystallographic data for this paper. These data can be obtained free of charge via www.ccdc.cam.ac.uk/ data_request/cif, or by emailing data_request@ccdc.cam.ac. uk, or by contacting The Cambridge Crystallographic Data Centre, 12 Union Road, Cambridge CB2 1EZ, UK; fax: +44 1223336033.

\section{AUTHOR INFORMATION}

\section{Corresponding Author}

Alexander H. Sandtorv - Department of Chemistry, University of Oslo, N-0315 Oslo, Norway; (1) orcid.org/0000-0003-

2480-0195; Email: a.h.sandtorv@kjemi.uio.no

\section{Authors}

Linn Neerbye Berntsen - Department of Chemistry, University of Oslo, N-0315 Oslo, Norway

Ainara Nova - Hylleraas Centre for Quantum Molecular Sciences, Department of Chemistry, University of Oslo, N-0315 Oslo, Norway; 이이이.org/0000-0003-3368-7702

David S. Wragg - Department of Chemistry, University of Oslo, N-0315 Oslo, Norway

Complete contact information is available at:

https://pubs.acs.org/10.1021/acs.orglett.0c00642

\section{Notes}

The authors declare no competing financial interest.

\section{ACKNOWLEDGMENTS}

L.N.B. gratefully acknowledges the Department of Chemistry at the University of Oslo for funding her Ph.D. fellowship. Arild X. Hagen (Department of Chemistry, University of Oslo) is acknowledged for technical assistance with the optimization study, and Brian C. Gilmour (Oslo University Hospital, University of Oslo) is acknowledged for technical assistance in the preparation of diaryliodonium salts. The project has received support from UiO: Life Science and was partially supported by the Research Council of Norway through the Norwegian NMR Platform, NNP (226244/F50). A.N. acknowledges the support from the Research Council of Norway (FRINATEK grant no. 250044 and Center of Excellence grant no. 262695). We acknowledge the use of the Norwegian national infrastructure for X-ray diffraction and scattering (RECX, Research Council of Norway project number 208896).

\section{REFERENCES}

(1) Konnert, L.; Lamaty, F.; Martinez, J.; Colacino, E. Chem. Rev. 2017, 117, 13757-13809.

(2) For some examples, see: (a) Sarges, R.; Goldstein, S. W.; Welch, W. M.; Swindell, A. C.; Siegel, T. W.; Beyer, T. A. J. Med. Chem. 1990, 33, 1859-1865. (b) Tan, L.; Maji, S.; Mattheis, C.; Zheng, M.; Chen, Y.; Caballero-Díaz, E.; Gil, P. R.; Parak, W. J.; Greiner, A.; Agarwal, S. Macromol. Biosci. 2012, 12, 1068-1076. (c) Su, M.; Xia, D.; Teng, P.; Nimmagadda, A.; Zhang, C.; Odom, T.; Cao, A.; Hu, Y.; Cai, J. J. Med. Chem. 2017, 60, 8456-8465. (d) Żesławska, E.; Kincses, A.; Spengler, G.; Nitek, W.; Tejchman, W.; Handzlik, J. Chem. Biol. Drug Des. 2019, 93, 844-853. (e) Cho, S.; Kim, S.-H.; Shin, D. Eur. J. Med. Chem. 2019, 164, 517-545. (f) Fetzer, C.; Korotkov, V. S.; Sieber, S. A. Org. Biomol. Chem. 2019, 17, 7124-7217.

(3) Mendgen, T.; Steuer, C.; Klein, C. D. J. Med. Chem. 2012, 55, $743-753$.
(4) Mizuno, T.; Kino, T.; Ito, T.; Miyata, T. Synth. Commun. 2000, $30,1675-1688$.

(5) (a) Khazaei, A.; Zolfigol, M. A.; Rostami, A. Synthesis 2004, 2959-2961. (b) Sandtorv, A. H.; Bjørsvik, H.-R. Adv. Synth. Catal. 2013, 355, 499-507. (c) Leitch, J. A.; Cook, H. P.; Bhonoah, Y.; Frost, C. G. J. Org. Chem. 2016, 81, 10081-10087. (d) Luo, Z.; Liu, T.; Guo, W.; Wang, Z.; Huang, J.; Zhu, Y.; Zeng, Z. Org. Process Res. Dev. 2018, 22, 1188-1199.

(6) (a) Burton, S. G.; Dorrington, R. A. Tetrahedron: Asymmetry 2004, 15, 2737-2741. (b) May, O.; Verseck, S.; Bommarius, A.; Drauz, K. Org. Process Res. Dev. 2002, 6, 452-457. (c) FernandezNieto, F.; Mas Rosello, J.; Lenoir, S.; Hardy, S.; Clayden, J. Org. Lett. 2015, 17, 3838-3841. (d) Abas, H.; Mas-Roselló; Amer, M. M.; Durand, D. J.; Groleau, R. R.; Fey, N.; Clayden, J. Angew. Chem., Int. Ed. 2019, 58, 2418-2422. (e) Amer, M. M.; Abas, H.; Leonard, D. J.; Ward, J. W.; Clayden, J. J. Org. Chem. 2019, 84, 7199-7206.

(7) For some examples, see: (a) Hamann, L. G.; Manfredi, M. C.; Sun, C.; Krystek, S. R., Jr.; Huang, Y.; Bi, Y.; Augeri, D. J.; Wang, T.; Zou, Y.; Betebenner, D. A.; Fura, A.; Seethala, R.; Golla, R.; Kuhns, J. E.; Lupisella, J. A.; Darienzo, C. J.; Custer, L. L.; Price, J. L.; Johnson, J. M.; Biller, S. A.; Zahler, R.; Ostrowski, J. Bioorg. Med. Chem. Lett. 2007, 17, 1860-1864. (b) Payen, O.; Top, S.; Vessieres, A.; Brule, E.; Plamont, M.-A.; McGlinchey, M. J.; Muller-Bunz, H.; Jaouen, G. J. Med. Chem. 2008, 51, 1791-1799. (c) Wang, C.; Zhao, Q.; Vargas, M.; Jones, J. O.; White, K. L.; Shackleford, D. M.; Chen, G.; Saunders, J.; Ng, A. C. F.; Chiu, F. C. K.; Dong, Y.; Charman, S. A.; Keiser, J.; Vennerstrom, J. L. J. Med. Chem. 2016, 59, 10705-10718. (d) Tamura, T.; Noda, H.; Joyashiki, E.; Hoshino, M.; Watanabe, T.; Kinosaki, M.; Nishimura, Y.; Esaki, T.; Ogawa, K.; Miyake, T.; Arai, S.; Shimizu, M.; Kitamura, H.; Sato, H.; Kawabe, Y. Nat. Commun. 2016, 7, 13384-13398. (e) Bauman, A.; Piel, M.; Höhnemann, S.; Krauss, A.; Jansen, M.; Solbach, C.; Dannhardt, G.; Rösch, F. J. Labelled Compd. Radiopharm. 2011, 54, 645-656.

(8) (a) Meusel, M.; Gütschow, M. Org. Prep. Proced. Int. 2004, 36, 391-443. (b) Konnert, L.; Lamaty, F.; Martinez, J.; Colacino, E. Chem. Rev. 2017, 117 (23), 13757-13809.

(9) For some recent examples, see: (a) Rajic, Z.; Zorc, B.; RaicMalic, S.; Ester, K.; Kralj, M.; Pavelic, K.; Balzarini, J.; De Clercq, E.; Mintas, M. Molecules 2006, 11, 837-848. (b) Zhao, B.; Du, H.; Shi, Y. J. Am. Chem. Soc. 2008, 130, 7220-7221. (c) Gao, M.; Yang, Y.; Wu, Y.-D.; Deng, C.; Shu, W.-M.; Zhang, D.-X.; Cao, L.-P.; She, N.-F.; Wu, A.-X. Org. Lett. 2010, 12, 4026-4029. (d) Bogolubsky, A. V.; Moroz, Y. S.; Savych, O.; Pipko, S.; Konovets, A.; Platonov, M. O.; Vasylchenko, O. V.; Hurmach, V. V.; Grygorenko, O. O. ACS Comb. Sci. 2018, 20, 35-43. (e) Saunthwal, R. K.; Cornall, M. T.; Abrams, R.; Ward, J. W.; Clayden, J. Chem. Sci. 2019, 10, 3408-3412. (f) Declas, N.; Le Vaillant, F.; Waser, J. Org. Lett. 2019, 21, 524-528. (g) Liu, S. L.; Haung, J.-Y.; Barve, I. J.; Huang, S.-C.; Sun, C.-M. ACS Comb. Sci. 2019, 21 (4), 336-344.

(10) (a) Hugel, H. M.; Rix, C. J.; Fleck, K. Synlett 2006, 2006, 2290-2292. (b) Bigg, D.; Auvin, S.; Lanco, C.; Prevost, G. Imidazolidine-2,4-dione Derivatives, Their Preparation and Use for Treating Hormone-Dependent Cancer. WO 2010119194 A1, 2010. (c) Cowley, P. M.; McGowan, M. A.; Brown, T. J.; Han, Y.; Liu, K.; $\mathrm{Pu}$, Q.; Wise, A.; Zhang, H.; Zhou, H. Novel Substituted Imidazopyridine Compounds as Inhibitors of indoleamine 2,3Dioxygenase and/or Tryptophan-2,3-dioxygenase. WO 2017189386 A1, 2017. (d) Qin, X.; Fang, L.; Zhao, J.; Gou, S. Inorg. Chem. 2018, 57, 5019-5029.

(11) Thilmany, P.; Gerard, P.; Vanoost, A.; Deldaele, C.; Petit, L.; Evano, G. J. Org. Chem. 2019, 84, 392-400.

(12) Preliminary communication: (a) Lopez-Alvarado, P.; Avendano, C.; Carlos Menendez, J. Tetrahedron Lett. 1992, 33, 6875-6878. Full report: (b) Lopez-Alvarado, P.; Avendano, C.; Menendez, J. C. J. Org. Chem. 1996, 61, 5865-5870. (c) Suresh, M.; Ravi, S.; Sudhakar, K. Synthesis of Nilutamide and Development of CN Bond Formation by Reusable Green Catalyst. IN 201741010702, 2017. (d) Pierce, J. M.; Hale, J. J.; Miao, S.; Vachal, P. Substituted1,3,8-triazaspiro[4.5]decane-2,4-diones. WO2010147776 A1, 2010. 
(e) Vachal, P.; Miao, S.; Pierce, J. M.; Guiadeen, D.; Colandrea, V. J.; Wyvratt, M. J.; Salowe, S. P.; Sonatore, L. M.; Milligan, J. A.; Hajdu, R.; Gollapudi, A.; Keohane, C. A.; Lingham, R. B.; Mandala, S. M.; DeMartino, J. A.; Tong, X.; Wolff, M.; Steinhuebel, D.; Kieczykowski, G. R.; Fleitz, F. J.; Chapman, K.; Athanasopoulos, J.; Adam, G.; Akyuz, C. D.; Jena, D. K.; Lusen, J. W.; Meng, J.; Stein, B. D.; Xia, L.; Sherer, E. C.; Hale, J. J. J. Med. Chem. 2012, 55, 2945-2959.

(13) For some reviews, see, for example: (a) Deprez, N. R.; Sanford, M. S. Inorg. Chem. 2007, 46 (6), 1924-1935. (b) Merritt, E. A.; Olofsson, B. Angew. Chem., Int. Ed. 2009, 48, 9052-9070. (c) Yusubov, M. S.; Maskaev, A. V.; Zhdankin, V. V. ARKIVOC 2011, 2011, 370-409. (d) Aradi, K.; Tóth, B. L.; Tolnai, G. L.; Novák, Z. Synlett 2016, 27, 1456-1485. (e) Olofsson, B. Top. Curr. Chem. 2015, 373, 135-166.

(14) Stuart, D. R. Chem. - Eur. J. 2017, 23, 15852-15863.

(15) For some recent examples, see: (a) Jalalian, N.; Ishikawa, E. E.; Silva, L. F.; Olofsson, B. Org. Lett. 2011, 13, 1552-1555. (b) Phipps, R. J.; McMurray, L.; Ritter, S.; Duong, H. A.; Gaunt, M. J. J. Am. Chem. Soc. 2012, 134, 10773-10776. (c) Sandtorv, A. H.; Stuart, D. R. Angew. Chem., Int. Ed. 2016, 55, 15812-15815. (d) Bhattarai, B.; Tay, J.-H.; Nagorny, P. Chem. Commun. 2015, 51, 5398-5401. (e) Modha, S. G.; Greaney, M. F. J. Am. Chem. Soc. 2015, 137, 14161419. (f) Aradi, K.; Mészáros, A.; Tóth, B. L.; Vincze, Z.; Novák, Z. J. Org. Chem. 2017, 82, 11752-11764. (g) Purkait, N.; Kervefors, G.; Linde, E.; Olofsson, B. Angew. Chem., Int. Ed. 2018, 57, 1142711431. (h) Wang, L.; Chen, M.; Zhang, J. Org. Chem. Front. 2019, 6, $32-35$.

(16) Metal-free coupling of imides with unsymmetric iodonoum salts is also known: Basu, S.; Sandtorv, A. H.; Stuart, D. R. Beilstein J. Org. Chem. 2018, 14, 1034-1038.

(17) Wijma, R. A.; Huttner, A.; Koch, B. C. P.; Mouton, J. W.; Muller, A. E. J. Antimicrob. Chemother. 2018, 73, 2916-2926.

(18) Huang, Q.; Liu, Q.; Ouyang, D. Med. Chem. 2019, 15, 3-7.

(19) Gurjar, K. K.; Sharma, R. K. ChemCatChem 2017, 9, 862-869.

(20) (a) Chen, B.; Hou, X.-L.; Li, Y.-X.; Wu, Y.-D. J. Am. Chem. Soc.

2011, 133, 7668-7671. (b) Ichiishi, N.; Canty, A. J.; Yates, B. F.; Sanford, M. S. Organometallics 2014, 33, 5525-5534.

(21) Allen, S. E.; Walvoord, R. R.; Padilla-Salinas, R.; Kozlowski, M. C. Chem. Rev. 2013, 113, 6234-6458.

(22) For similar acetate-assisted deprotonation reactions, see: Davies, D. L.; Macgregor, S. A.; McMullin, C. L. Chem. Rev. 2017, 117, 8649-8709. 